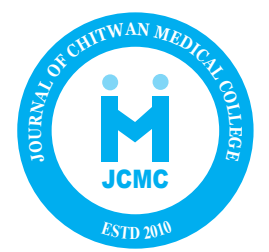

Journal of Chitwan Medical College 2016;6(17): 26-32

Available online at: www.jcmc.cmc.edu.np

ORIOTLL BESERRGI ARTIGL

\title{
EPIDURAL BUTORPHANOL FOR POST OPERATIVE ANALGESIA IN LOWER LIMB SURGERIES: A COMPARATIVE STUDY WITH EPIDURAL TRAMADOL
} GP Deo ${ }^{1 *}$, SK Shrestha ${ }^{1}$, IN Shrestha ${ }^{1}$

${ }^{1}$ Department of Anaesthesiology \& Critical Care, Chitwan Medical College, Bharatpur, Nepal

*Correspondence to: Dr Gopendra Prasad Deo, Department of Anaesthesiology \& Critical Care, Chitwan Medical College, Bharatpur, Nepal.

Email: gopendradeo@gmail.com

\begin{abstract}
To compare the efficacy of epidural butorphanol and tramadol for post operative analgesia in lower limb surgeries. Randomized, controlled, double blind, prospective study conducted at Department of Anaesthesia and Critical Care, Chitwan Medical College from September 1st 2015 to August 31st 2016. 60 patients of ASA Grade I and II of either sex, aged between 18-65 years willing for epidural analgesia for post operative analgesia were included in the study. They were divided into two groups: Group B- Butorphanol group and Group T- Tramadol group. Subjects of Group B received 2mg of Butorphanol and $0.25 \%$ Bupivacaine making a total volume of $10 \mathrm{ml}$ and that of Group T received $100 \mathrm{mg}$ of Tramadol and $0.25 \%$ Bupivacaine also making a total volume of $10 \mathrm{ml}$. Analgesic efficacy was assessed by Visual Analogue Scale (VAS). The onset and duration of analgesia along with side effects were also assessed. The quality of analgesia was studied using time to independent mobilization and overall patient satisfaction. Total number of patients was 60, of ASA Grade I and II, aged between $18-65$ years. The mean age of patients in Group B was $42.6 \pm 11.7$ years and $46.1 \pm 11.2$ years in Group T. Time of onset of analgesia after epidural injection was $7.4 \pm 0.9$ minutes in Group B and $12.7 \pm 1.5$ minutes in Group T and the difference was found to be statistically significant. Duration of analgesia was $317.1 \pm 99.1$ minutes and $438.8 \pm 136.6$ minutes in Butorphanol and Tramadol groups respectively which was also statistically significant. Sedation was significantly higher in butorphanol group whereas nausea and vomiting was higher in tramadol group. Quality of analgesia in terms of patient satisfaction was better with epidural butorphanol. Both epidural tramadol and butorphanol were effective in relieving post operative pain however butorphanol had lesser side effects and greater patient satisfaction compared to tramadol but the duration of action was relatively short.
\end{abstract}

Key words: Butorphanol, Epidural analgesia, Post-operative analgesia, Tramadol.

\section{INTRODUCTION}

Adequate postoperative pain management is an integral part of the management of all surgeries. Postoperative pain gives rise to various physiological and psychological phenomenon and can be detrimental to health and recovery of patients. The provision of good quality post operative analgesia is important not only to ease patients suffering and induce sense of well being, but also vital for early mobilization, less post operative complications and early discharge ${ }^{1}$.

Epidural analgesia remains superior route for thoraco-abdominal and lower limb surgeries since it preserves the pulmonary function and provides early mobilization with lesser risk of deep vein thrombosis. Epidural administration of local anesthetics produces adequate analgesia albeit of a shorter duration and so, to prolong it, opioids are added. Epidural morphine provides good post operative analgesia but is associated with undesirable side effects like respiratory depression, urinary retention, nausea, vomiting and pruritus ${ }^{2}$.

Both butorphanol, a mixed agonist antagonist opioid and tramadol, a moderately potent opioid agonist has been used for postoperative analgesia. So, this prospective, randomized, controlled, double blind study was designed to compare the efficacy of epidural butorphanol and tramadol as post operative analgesics. 


\section{MATERIAL AND METHODS}

After obtaining approval of CMC-IRC and informed consent, 60 patients with ASA physical status I and II of either sex between 18 to 65 years undergoing lower limb surgeries were included. Exclusion criteria included were patient's refusal for epidural analgesia or subarachnoid block, ASA physical status III or more, age less than 18 years and more than 65 years, failed or partial effect of subarachnoid block, history of hypersensitivity to butorphanol or local anesthetics, uncontrolled hypertension, known coronary artery disease and patient requiring general anaesthesia. Patients were familiarized with visual analogue scale (VAS) scoring pre-operatively and taught to grade their pain on scale.

All patients were premedicated with tablet Diazepam $(0.2 \mathrm{mg} / \mathrm{kg}$ body weight), the night before and Ranitidine $150 \mathrm{mg}$ and Alprazolam 0.25 mg orally as premedicants 2 hours before surgery. In the operation theatre, an intravenous line was secured and was connected to multichannel monitor showing electrocardiography, noninvasive blood pressure (NIBP), respiratory rate and pulse oximeter. The patients were preloaded with lactated ringer solution $15 \mathrm{ml} / \mathrm{kg}$ over 15 to 30 minutes. All the patients were planned under combined spinal epidural anaesthesia.

After proper positioning, with all aseptic precautions, local anaesthesia was infiltrated. Then epidural space was identified in $L_{2}-L_{3}$ or $L_{3}-L_{4}$ space using 18G Tuohy's needle using loss of resistance to air technique. An epidural catheter was introduced through the Tuohy's needle and was advanced 3-4 $\mathrm{cm}$ in the epidural space. Correct placement of catheter was checked with a test dose of $3 \mathrm{ml}$ of 2\% lidocaine with epinephrine (1: 200000) given through epidural catheter. Following insertion of the epidural catheter, subarachnoid block was given to all the patients, using a 25 gauge Quincke Babcock needle, through an intervertebral space below the epidural catheter insertion. After free flow of clear cerebrospinal fluid, a dose of $0.3 \mathrm{mg} / \mathrm{kg}$ body weight of hyperbaric $0.5 \%$ bupivacaine was injected. Patient was then positioned as needed for the surgery. No opioids or sedatives were given via any route to any of the patients in perioperative period.

During resolution of subarachnoid block, post- operative pain was evaluated using a $100 \mathrm{~mm}$ visual analogue scale (VAS) which consists of $100 \mathrm{~mm}$ line drawn on a $3 \times 5$ inch card with 0 indicating no pain while 100 represents worst imaginable pain. The post operative pain assessment was done by an observer unaware of assigned medication group. Each patient was instructed to mark the scale at the point which he or she felt was representative of level of pain. When the patient indicated that pain was $40 \mathrm{~mm}$ or more or asked for pain relief, study medication was given via epidural catheter according to their assigned group in a double blind fashion.

The groups were:

Group B - Bupivacaine 0.125\% + Butorphanol $2 \mathrm{mg}$ (total volume $=10 \mathrm{ml}$ )

Group T - Bupivacaine 0.125\% + Tramadol $100 \mathrm{mg}$ (total volume $=10 \mathrm{ml}$ )

The study drugs were prepared by a doctor who was not a part of the team. Patients were randomly allocated into 2 groups of 30 patients each by computer generated randomization. The study was carried out in double blind fashion by making 60 coded slips. The person performing the procedure and carrying out the observation was blinded to the drug solution injected. Each medication was diluted to a total of $10 \mathrm{ml}$ with sterile preservative free saline injection. The $10 \mathrm{ml}$ syringe containing the study drug was labeled with patient's code number. Each patient was instructed that he or she could request for supplemental medication at any time during the study.

Baseline visual analogue score (VAS) along with blood pressure, respiratory rate, pulse rate was recorded at the time of epidural drug administration and was then monitored continuously for one hour in post operative care unit for onset of analgesia (VAS reduction by $10 \mathrm{~mm}$ ), time to VAS score $<10 \mathrm{~mm}$ if achieved and lowest VAS score $\left(\right.$ VAS $_{\min }$ ) and corresponding physiological parameters. The patients were then monitored half hourly until VAS is more than $40 \mathrm{~mm}$ or asked for pain relief. Once patient asked for pain relief or VAS was more than 40 , the allocated medication was given epidurally and this was used as end of patient's participation in the study. 
The following pain variables were determined:

The onset of analgesia was defined as the time in minutes from full injection of the study medication to initial reduction in pain intensity (using VAS) of at least $10 \mathrm{~mm}$ on two consecutive evaluations ${ }^{3}$.

$>\quad$ Time to VAS score $<10 \mathrm{~mm}^{3}$

$>\quad$ Lowest VAS score $\left(\text { VAS }_{\min }\right)^{3}$

$>$ The duration of analgesia was defined as the time between onset of analgesia and either a return to baseline VAS or the time when additional pain medication was requested (whichever occurs first) ${ }^{3}$.

$>\quad$ VAS pain scores when the patient received the study medication (VAS baseline) and VAS scores when patient requested additional medication (VASend) ${ }^{3}$.

Patient who reported no decrease in VAS for 30 minutes and requested for additional analgesics within 30 minutes was given injection Pethidine intravenously as rescue medication and assuming epidural catheter not in proper place, the patient was excluded from the study.

When a patient requested for analgesia after cessation of the effect of first dose of study medication, the time interval immediately preceding the request was used as the end point of study duration and second dose of study drug was injected. No patient was withheld of analgesic at any time for the purpose of the study. The quality of analgesia was assessed by patient satisfaction and time to independent mobilization (the time patient started sitting independently from supine position). Overall satisfaction of the patient was assessed by using 100 points visual analogue scale (0 no satisfaction, 100 best satisfaction $)^{4}$.

Side effects and complication;

Patients were monitored closely to observe and treat any complications.

Each patient was evaluated 4 hourly for the next 24 hours for side effects like sedation, nausea, vomiting, pruritus and hallucination. On occurrence of any of the side effect, it was treated accordingly when needed.

Sedation Score ${ }^{5}$

0 . Awake and oriented

1. Dozing intermittently but easily arousable

2. Sedated, sleeping but arousable

3. Difficult to arouse or unarousable

Nausea Vomiting Score

0 . No nausea, no vomiting

1. Light nausea, one episode of vomiting

2. Moderate nausea, two vomiting episode

3. Severe nausea, three or more vomiting episodes

Respiratory Depression Score ${ }^{7}$

1. Normal rate

2. $8-12$ breaths/min

3. $<8$ breaths/min

Pruritus Score ${ }^{8}$

0 . No pruritis

1. Mild pruritus, no treatment required

2. Moderate pruritus, treatment required

Statistical analysis:

After the study was completed, the data were coded and decoded and patients were sorted into two groups on the basis of drug administered. Data were analysed on the basis of numerical or categorical variable. In numerical variable, Parametric test as independent t test was applied and in categorical variable, nonparametric test as Chi square test was applied to identify whether the data was statistically significant or not. Data were entered in a master chart in MS Excel 2007 and analyzed by Statistical Package for Social Science (IBM SPSS) version 20. Findings were considered statistically significant when $p$-value was less than 0.05 and were considered highly significant when $p$-value was less than 0.001 . 


\section{RESULTS}

Sixty cases were taken in the study, having ASA physical status Grade I and II, aged between 18-65 years willing for epidural analgesia for post-operative analgesia in the duration from $1^{\text {st }}$ Sept. 2015 to $31^{\text {st }}$ Aug. 2016 in Department of Anaesthesia and Critical Care, Chitwan Medical College and Teaching
Hospital. They were divided into 2 equal groups. All 60 patients enrolled completed the study. No technical difficulty or inadvertent dural puncture was encountered. Both groups were comparable with regards to age, sex, weight, duration of surgery and time from end of surgery to epidural administration of study medication (table 1).

Table 1: Distribution of demographic data of patients

\begin{tabular}{|l|l|l|l|l|}
\hline \multicolumn{2}{|l}{ Parameters } & Group B & Group T & P value \\
\hline Age (years) & Mean \pm SD & $42.6 \pm 11.7$ & $46.1 \pm 11.2$ & $0.245^{\Delta}$ \\
\hline \multirow{2}{*}{ Sex } & Male & $12(40 \%)$ & $13(43.3 \%)$ & \multirow{2}{*}{$0.793^{\Psi}$} \\
\cline { 2 - 5 } & Female & $18(60 \%)$ & $17(56.7 \%)$ & \\
\hline Weight & Mean $\pm S D$ & $54.6 \pm 11.3$ & $53.6 \pm 6.3$ & $0.695^{\tau}$ \\
\hline Duration of Surgery (minutes) & Mean \pm SD & $87.0 \pm 20.8$ & $85.8 \pm 25.7$ & $0.847^{\Delta}$ \\
\hline Time to study medication (minutes) & Mean $\pm S D$ & $50.7 \pm 14.1$ & $52.3 \pm 19.3$ & $0.673^{\Delta}$ \\
\hline
\end{tabular}

${ }_{\Delta}$ P-value computed by equal variance assumed by independent $t$ test, ${ }^{\psi}{ }^{*} p$-value computed by chi square test, ${ }^{\top} \mathrm{P}$-value computed by unequal variance assumed by independent $\mathrm{t}$ test.

All the baseline parameters at the time of study medication including VAS $_{\text {baseline }}$ were comparable. (Table 2)

Table 2: Baseline parameters at the time of administration of study medication among the groups

\begin{tabular}{|l|l|l|l|}
\hline Parameters & Group B & Group T & P value \\
\hline Vas Baseline $(\mathrm{mm})$ & $42.0 \pm 4.1$ & $42.3 \pm 6.3$ & 0.808 \\
\hline HR $(\mathrm{bpm})$ & $82.8 \pm 11.2$ & $85.7 \pm 9.9$ & 0.299 \\
\hline SBP $(\mathrm{mmHg})$ & $124.6 \pm 13.1$ & $126.2 \pm 10.3$ & 0.601 \\
\hline DBP $(\mathrm{mmHg})$ & $80.8 \pm 9.4$ & $81.8 \pm 8.0$ & 0.669 \\
\hline RR (per min) & $16.7 \pm 2.6$ & $18.5 \pm 2.9$ & $\mathbf{0 . 0 1 4}$ \\
\hline
\end{tabular}

P-value computed by equal variance assumed by independent $t$ test, $p$-value $<0.05$ is considered to be significant.

The onset of analgesia was faster with butorphanol but the duration of analgesia was longer with tramadol (Table 3).

Table 3: Pharmacokinetic Profile: Onset of analgesia

\begin{tabular}{|l|l|l|l|}
\hline Parameters & Group B & Group T & P value \\
\hline Onset time (min) & $7.4 \pm 0.9$ & $12.7 \pm 1.5$ & $<0.001$ \\
\hline Duration of analgesia (min) & $317.1 \pm 99.1$ & $438.8 \pm 136.6$ & $<0.001$ \\
\hline
\end{tabular}

P-value computed by unequal variance assumed by independent $t$ test, $p$-value $<0.05$ is considered to be significant.
Table 4 shows sedation was higher in Butorphanol Group however nausea \& vomiting was seen in Tramadol Group .

Table 4: Side Effects

\begin{tabular}{|l|l|l|l|}
\hline Parameters & Group B & Group T & P-Value \\
\hline Sedation & $\begin{array}{l}28 \\
(93.3 \%)\end{array}$ & $\begin{array}{l}13 \\
(43.33 \%)\end{array}$ & $<0.001$ \\
\hline Nausea \& Vomiting & 0 & $4(13.33 \%)$ & 0.002 \\
\hline Pruritus & 0 & 1 & \\
\hline $\begin{array}{l}\text { Respiratory } \\
\text { Depression }\end{array}$ & 0 & 0 & \\
\hline Bradycardia & 0 & 0 & \\
\hline Dry Mouth & 0 & 0 & \\
\hline Hallucination & 0 & 0 & \\
\hline
\end{tabular}


Table 5 shows even though there was no statistically significant difference between two groups in terms of time to independent mobilization, satisfaction was better with Butorphanol.

Table 5: Quality of analgesia

\begin{tabular}{|l|l|l|l|}
\hline Parameters & Group B & Group T & $\begin{array}{l}\text { P- } \\
\text { value }\end{array}$ \\
\hline $\begin{array}{l}\text { Time to independent } \\
\text { mobilization (hrs) }\end{array}$ & $30.6 \pm 6.4$ & $31.7 \pm 5.6$ & 0.453 \\
\hline Satisfaction & $85.3 \pm 7.8$ & $78.0 \pm 9.6$ & 0.002 \\
\hline
\end{tabular}

P-value computed by equal variance assumed by independent $t$ test, $p$-value $<0.05$ is considered to be significant

\section{DISCUSSION}

Effective postoperative pain control is an important component of postoperative recovery and a prime concern for anaesthesiologists. The goal of modern postoperative pain management is to minimize suffering and enhance recovery and rehabilitation through blunting maladaptive reflexes ${ }^{3}$. Epidural route is being used extensively for post operative pain control. The advantages of epidural route include the use of lower doses, longer duration of effects and lower incidence of side effects ${ }^{9}$. Combined spinal epidural anaesthesia finds a common place for perioperative management of lower limb surgeries, having advantages of both spinal anaesthesia and epidural analgesia, initially providing an intense sensory and motor blockade of rapid onset, followed by post operative pain management by epidural analgesia, after regression of spinal analgesia.

Epidural injection of local anesthetics provides good analgesia at the cost of motor block and sympathetic block. Motor block is quite distressing as it delays mobilization and sympathetic block may cause hypotension. In addition, it has shorter duration of action ${ }^{9}$. Epidural morphine is effective in relieving post operative pain for longer duration but is associated with delayed respiratory depression, urinary retention, nausea \& vomiting along with pruritus $^{10}$. So, this prospective, randomized, double blind dose response study was designed to compare the efficacy of epidural butorphanol and tramadol as post operative analgesics.
This study involved 60 patients randomized in 2 equal groups. All the patients had received total of $10 \mathrm{ml}$ of $0.125 \%$ of plain bupivacaine with either 2 $\mathrm{mg}$ of butorphanol in group B or $100 \mathrm{mg}$ of tramadol in group $\mathrm{T}$. The mean time of onset of analgesia was $7.4 \pm 0.9$ minutes in group $B$ and $12.7 \pm 1.5$ minutes in group $T$ suggesting onset was faster with epidural butorphanol. The results were comparable with the study done by Swathi et $\mathrm{al}^{11}$ which also showed that onset of action was faster with butorphanol. Our study shows that tramadol had a longer duration of analgesia compared to butorphanol for postoperative epidural analgesia and the results were statistically significant. Mean duration of action of epidural butorphanol was $317 \pm 99.1$ minutes and that of epidural tramadol was $438.8 \pm 136.6$. Similar results were found in the study done by Swathi et $\mathrm{al}^{11}$ and Gupta et $\mathrm{al}^{12}$.

Comparing VAS scores, it was found that VAS score was not statistically significant between two groups before giving drugs. After 30 minutes, it was found that VAS score was significantly lower in both groups. VAS scores were significantly lower in Butorphanol group than Tramadol group at various time intervals suggesting that pain relief was significantly better in Butorphanol group. Significant reduction in VAS scores were also observed by Swathi ${ }^{11}$ et al, Pokharel et $\mathrm{al}^{13}$, Bharti et $\mathrm{al}^{14}$, Palacios et $\mathrm{al}^{15}$ and Rawal et $\mathrm{al}^{16}$.

Nausea and vomiting was observed in none of the patients in Group B and 4 patients in group $T$ which is statistically significant. Tramadol is known to cause higher incidence of nausea and vomiting ${ }^{17}$. So drugs to control nausea and vomiting should be given when tramadol is used. Sedation was seen in 28 out of 30 patients of Group B and 13 out of 30 patients in group $T$ which was highly significant $(p<0.001)$. Mild sedation is desirable in the post operative period. Higher incidence of sedation in Butorphanol group and higher incidence of nausea and vomiting in Tramadol group were also seen in study done by Abboud et $\mathrm{al}^{10}$ and Gupta et $\mathrm{al}^{12}$. Patients who received epidural butorphanol reported significantly higher level of somnolence in a similar study done by Gambling et al. ${ }^{18}$ Similarly, in the study done by Bailey et $\mathrm{al}^{19}$ sedation was seen more frequently in the groups receiving butorphanol. Pruritis was observed in 1 of the patient who received tramadol. 
None of our patients ever had a respiratory rate of less than 12 breaths/min. The finding was similar with the studies done by Abboud et $\mathrm{al}^{10}$ and Palacios et $a^{15}$. All the patients maintained a respiratory rate greater than 12 throughout the study period in the similar study done by Hunt et $\mathrm{al}^{20}$.

We have used time to independent mobilization and patient's satisfaction to assess quality of analgesia and have inferred that quality of analgesia is better with butorphanol. Though there was no statistically significant difference in time to independent mobilization, overall satisfaction was better with butorphanol and the results were found to be statistically significant $(p=0.002)$ [Table 5].

There are some obvious limitations of our study. First, although epidural administration of tramadol has been extensively used for analgesia by numerous investigators in clinical studies, more studies are needed to assess the safety of its intrathecal administration for post operative analgesia. Second, clinically significant respiratory depression was not observed in our study but respiratory rate being less sensitive, it is better to measure $\mathrm{PaCO}_{2}$. Not measuring $\mathrm{PaCO} 2$ was a limiting factor in our study. Third, the result of our study could have been more precise if the sample size of study group would have been large, but the patients who gave consent for epidural analgesia were limited in our institution.

Thus it can be concluded from this study that epidural Butorphanol is a safe and effective method of providing post operative pain relief with lesser side effects and greater patient satisfaction compared to tramadol but of relatively shorter duration.

\section{REFERENCES}

1. Jayr C, Thomas H, Rey A, Farhat F, Lasser P, Bourgain JL. Post operative complications of epidural analgesia using bupivacaine and opioids versus parental opioids. Anesthesiology 1993;78:666-76.

2. Reiz S, Westberg M. Side effects of epidural morphine. Lancet 1980;2(8187):203-4.

3. Grass JA, Sakima NT, Schmidt R, Michitsch R, Zuckerman RL, Harris AP. A randomized double blind dose response comparison of epidural fentanyl versus sufentanil analgesia after Caesarean Section. Anesth Analg 1997;85:36571.

4. Yu PYH, Gamling DR. A comparative study of patient controlled epidural fentanyl and single dose epidural morphine for post cesarean section. Can J Anaesth 1993;40(5):416-20.

5. Thomson CA, Becker DR, Messick CM, de Castro MA, Pairolero PC, Trastek VF et al. Analgesia after thoracotomy: Effects of epidural fentanyl concentration/infusion rate. Anesth Analg 1995;81:973-81.

6. Callesen T, Schouenborg L, Nielsen D, Guldager $\mathrm{H}$, Kehlet $\mathrm{H}$. Combined spinal epidural opioid free anaesthesia and analgesia for hysterectomy. Br J Anaesth 1999;82(6):881-85.

7. Brodners G, Mertes N, Aken HV, Pogatzki E, Buerkle $\mathrm{H}$, Marcus MA et al. Epidural analgesia with local anaesthetic agents after abdominal surgery-earlier motor recovery with $0.2 \%$ ropivacaine than $0.175 \%$ bupivacaine. Anesth Analg 1999;88:128-33.

8. Camann WR, Hurley RH, Gilbertson LI, Long ML, Mary L, Datta S. Epidural nalbuphine for post operative analgesia following cesarean delivery a dose response and effect of local anaesthetic choice. Can J Anaesth 1991;38(6):728-32.

9. Raj PP. Conduction block. In: Text book of regional anaesthesia. Newyork: Churchill Livingstone; 2002. p. 292-95.

10. Abboud TK, Moore M, Zhu J, Murakawa K, Minehart $M$, Longhitano $M$, et al. Epidural butorphanol or morphine for the relief of postcesarean section pain: ventilatory responses to carbon dioxide. Anesth Analg. 1987;66:887-93.

11. Swathi N, Ashwini N, Shukla MI. Comparative study of epidural bupivacaine with butorphanol and bupivacaine with tramadol for postoperative pain relief in abdominal surgeries. Anesth Essays Res 2016;10:462-7.

12. Gupta R, Kaur S, Singh S, Aujla KS. A comparison of epidural butorphanol and tramadol for postoperative analgesia using CSEA technique. J 
Deo et al, Journal of Chitwan Medical College 2016; 6(17)

Anaesthesiol Clin Pharmacol 2011;27:358.

13. Pokharel K, Rahman TR, Singh SN, Bhattarai B, Basnet $\mathrm{N}$, Khaniya S. The efficacy and safety of low dose epidural butorphanol on postoperative analgesia following cesarean delivery. JNMA J Nepal Med Assoc 2008;47:5761.

14. BhartiN, ChariP.Epidural butorphanolbupivacaine analgesia for postoperative pain relief after abdominal hysterectomy. J Clin Anesth 2009;21:1922.

15. Palacios TQ, Jones MM, Hawkins JL, Adenwala JN, Longmire $S$, Hess KR, et al. Post- Cesarean section analgesia: A comparison of epidural butorphanol and morphine. Can J Anaesth. 1991;38:24-30.

16. Rawal HH, Swadia VN, Patel HJ. Epidural tramadol bolus and continuous infusion. Indian J Anaesth. 1995;43:193-7.
17. Budd K, Langford R. Tramadol revisited. $\mathrm{Br} \mathrm{J}$ Anaesth 1999; 82(4): 493-5.

18. Gambling DR, Howell P, Huber C, Kozak S. Epidural butorphanol does not reduce side effects from epidural morphine after cesarean birth Anesth Analg 1994; 78(6): 1099-104.

19. Bailey AG, Valley RD, Fried EB, Calhoun P. Epidural morphine combined with epidural or intravenous butorphanol for postoperative analgesia in pediatric patients. Anesth Analg 1994; 79(2): 340-44.

20. Hunt CO, Naulty JS, Malinow AM, Datta S, Ostheimer GW. Epidural butorphanolbupivacaine for analgesia during labor and delivery. Anesth Analg 1989;68:3237. 